\title{
АНАЛИЗ ПСИХОВЕГЕТАТИВНОГО СТАТУСА У ПАЦИЕНТОВ С ИШЕМИЧЕСКИМ ПОВРЕЖДЕНИЕМ ГОЛОВНОГО МОЗГА
}

\author{
${ }^{1}$ Смычек В.Б., ${ }^{2}$ Галиновская Н.В., ${ }^{2}$ Латышева В.Я., ${ }^{2} У$ сова Н.Н., *

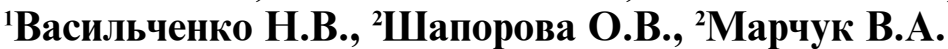 \\ ${ }^{1}$ Государственное учреждение «Республиканский научно-практический центр медицинской \\ экспертизы и реабилитаџии», Минск, Беларусь; \\ ${ }^{2}$ Учреждение образования «Гомельский государственный медицинский университет», Гомель, \\ Беларусь
}

Введение. Цереброваскулярная патология является лидирующей причиной смертности и выхода на первичную инвалидность $[1,8]$. У большинства пациентов, выживших после мозговой катастрофы, сохраняется неврологический дефицит $[8,11]$, когнитивные и нейропсихологические нарушения $[2,5,10]$. С введением единой системы профилактических мероприятий, направленных на коррекцию артериальной гипертензии (АГ), удельный вес кровоизлияний в общей структуре значительно снизился $[1,8]$, поэтому более пристального внимания заслуживает патогенез и профилактика инфаркта мозга (ИМ).

Предиктором ИМ считаются преходящие нарушения мозгового кровообращения (ПНМК) - остро возникающие изменения мозговых функций сосудистого генеза, проявляющиеся очаговой и (или) общемозговой симптоматикой и регрессирующие в течение 24 часов $[1,9]$. К ПНМК относят транзиторную ишемическую атаку (ТИА) - кратковременный эпизод неврологической дисфункции, вызванный фокальной церебральной или ретинальной ишемией с симптоматикой не более суток, без очевидных признаков острого ИМ и церебральный гипертонический криз (ЦГК) - изменение мозгового кровообращения в результате значительного повышения артериального давления, сопровождающееся появлением или усугублением имевшейся ранее симптоматики [9].

Изучению психоэмоциональных нарушений в остром и восстановительных периодах ИМ посвящено большое количество работ $[2,3,5,10]$. Однако публикаций по исследованию психологического и субъективного вегетативного статуса у па*email: nata_usova@mail.ru циентов с ПНМК недостаточно. Ранее нашими данными было показано, что при отсутствии очага поражения головного мозга по данным нейровизуализации при ТИА имеют место изменения психоэмоционального статуса, которые оказывают влияние на клиническую картину заболевания [6].

Цель работы: определение психовегетативного статуса при различных формах ишемического повреждения головного мозга.

Материалы и методы. Исследование проводилось на базе I неврологического отделения Гомельского областного клинического госпиталя ИОВ. Был обследован 171 человек (чел.): 22 - с большим по данным нейровизуализации ИМ (БИ) (9 женщин и 13 муж-

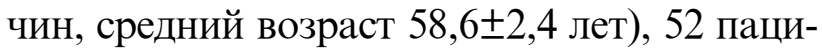
ента с лакунарным (ЛИ) (объем поражения мозгового вещества не превышал 16 мм) (28 женщин и 24 мужчины, средний возраст $50,6 \pm 1,7$ лет), 54 чел. с ТИА (28 женщин и 26 мужчин, средний возраст 56,2 2,2 лет) и 12 пациентов с ЦГК (10 женщин и 2 мужчин,

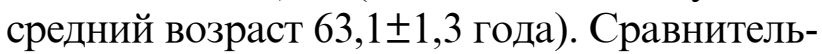
ную группу составили пациенты с ишемической болезнью сердца (ИБС), в которую входило 14 чел. (6 женщин и 8 мужчин, средний возраст $68,1,6 \pm 1,4$ лет). Контрольную группу представляли 17 здоровых добро-

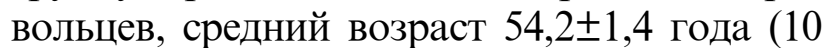
женщин и 7 мужчин). Все группы во время пребывания в стационаре проходили клиническое обследование, согласно протоколам диагностики и лечения, утвержденным Министерством здравоохранения Республики Беларусь. При осуществлении исследования у пациентов или законных представителей было получено информированное согласие. 
Проведение работы было одобрено этическим комитетом УО «Гомельский государственный медицинский университет».

Диагноз каждой нозологической формы выставлялся в соответствие с общепринятой клинической классификацией [9]. Выраженность неврологического и функционального дефицита у пациентов с ИМ была объективизирована с помощью шкалы инсульта Американского национального института здоровья (NIHSS) и шкалы оценки нарушений жизнедеятельности Бартела. При этом тяжесть неврологических нарушений у пациентов с ИМ составила на 1-е сутки по шкале NIHSS: для ЛИ $5,8 \pm 0,4$ баллов, для БИ -12,2 $\pm 0,5$. По шкале Бартела в этот же период пациенты показали $69,3 \pm 0,4$ баллов для ЛИ и $34,1 \pm 0,5$ для БИ. На момент выписки из отделения оценка по шкале NIHSS составляла:

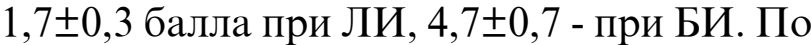

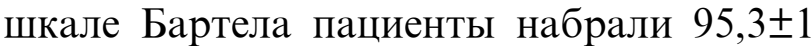
баллов у лиц с ЛИ и 78,2士3,9 - при БИ.

В клинической картине пациентов с ТИА преобладали жалобы на онемение правых или левых конечностей $(31,4 \%, 17$ чел.), слабость в них (31,4\%, 17 чел.), головокружение $(25,9 \%, 16$ чел.), головную боль $(27,8 \%, 15$ чел.), нарушение речи (16,7\%, 9 чел.). При поступлении объективно выявлены: лево- или правосторонний гемипарез (35,2\%): в $24,1 \%$, 13 чел. - легкий, в 5,6\%, 3 случаях - умеренный, в 5,6\% (3 чел.) - выраженный; гипестезия в половине лица или тела в 27,8\% (15 чел.); сглаженность носогубной складки 53,7\% (29 чел.); неустойчивость в позе Ромберга 48,1\% (26 чел.); асимметрия глубоких рефлексов и односторонний симптом Бабинского 50\% (27 чел.); гипестезия в половине лица или тела 31,9\% (15 чел.). Лица с ЦГК преимущественно предъявляли жалобы на головокружение $66,7 \%$ (8 чел.), головную боль 50\% (6 чел.), тошноту 50\% (6 чел.). Объективно было выявлено: легкий лево- или правосторонний гемипарез 41,7\% (5 чел.), статокинетические нарушения 58,3\% (7 чел), асимметрия оскала $33,3 \%$ (4 чел.), признаки односторонней пирамидной недостаточности 33,3\% (4 чел.).
Уровни личностной (ЛТ) и реактивной тревожности (РТ) изучался методом опроса с использованием шкалы Спилбергера-Ханина [11]. Под ЛТ понималась относительно устойчивая индивидуальная характеристика, дающая представление о предрасположенности человека к склонности воспринимать широкий круг ситуаций как угрожающие и реагировать на них состоянием тревоги различного уровня. РТ характеризовала субъективно переживаемое эмоциональное напряжение, сопровождающиеся активизацией вегетативной нервной системы (BНC). Показатель ниже 30 баллов свидетельствовал о слабой тревожности, от 31 до 45 - умеренной, свыше 45 - высокой [11]. Для диагностики депрессии применялась шкала депрессии Бека [11]. При результате менее 10 баллов регистрировалось отсутствие депрессии, 11-19 - легкая депрессия, 20-28 - средней тяжести, 29-63 - тяжелая. Определения параметров субъективного вегетативного статуса нами проводилось с помощью заполнения вегетативного опросника (BO) Вейна А.М., [4]. наличие вегетативной дистонии регистрировалось при результате более 18 баллов.

Статистический анализ данных проводили с помощью методов описательной и непараметрической статистики на базе программы «STATISTICA» 7.0. Данные, не соответствующие нормальному распределению, были представлены нами в виде медианы (Мед) и верхнего-нижнего квартилей (ЛГ-УГ). Для оценки различий между двумя независимыми группами использовали критерий Манна-Уитни. К достоверным различиям относили значение $\mathrm{p}<0,05$, тенденцией к отличию считали показатель $\mathrm{p}<0,1$. Корреляционный анализ проводили с использованием непараметрического критерия Спирмена.

Результаты и обсуждение. Согласно представленным в таблице 2 данным, наиболее высокий уровень Лт был выявлен у пациентов с ИБС (50 баллов, 46-56; при контрольном показателе 43,5 балла, 4149,5; p<0,01); который также был выше, чем в группах ЛИ (p<0,05)и ТИА $(\mathrm{p}<0,05)$. 
Таблица 2 - Распределение параметров психовегетативного статуса у пациентов с ишемическим повреждением головного мозга в группе сравнения и в контроле

\begin{tabular}{|c|c|c|c|c|c|c|c|c|c|c|c|c|}
\hline \multirow{3}{*}{$\begin{array}{l}\text { Пока- } \\
\text { затель }\end{array}$} & \multicolumn{12}{|c|}{ Клиническая форма } \\
\hline & \multicolumn{2}{|c|}{ БИ } & \multicolumn{2}{|c|}{ ЛИ } & \multicolumn{2}{|c|}{ ТИА } & \multicolumn{2}{|c|}{ ЦГК } & \multicolumn{2}{|c|}{ ИБС } & \multicolumn{2}{|c|}{ контроль } \\
\hline & $\overline{M e d}$ & LQ-UQ & Med & LQ-UQ & Med & $\begin{array}{l}\text { LQ-UQ } \\
\end{array}$ & Med & LQ-UQ & Med & LQ-UQ & Med & LQ-UQ \\
\hline $\begin{array}{c}\text { ЛТ, } \\
\text { балл }\end{array}$ & 47 & $43-56$ & 46,5 & $40,5-55$ & 47 & $42-53,5$ & 49 & $44-52$ & $50 *,{ }^{\circ}, \#$ & $46-56$ & 43,5 & $41-49,5$ \\
\hline $\begin{array}{c}\text { РТ, } \\
\text { балл } \\
\end{array}$ & 46 & $40-50$ & 44 & $41-49$ & 44 & $\begin{array}{l}39,5- \\
49,5\end{array}$ & $41 \# \#$ & $34-48$ & 46 & $38-50$ & 43 & $42-48$ \\
\hline $\begin{array}{l}\text { Бек, } \\
\text { балл }\end{array}$ & 4 & $2,5-6,5$ & 4 & $2-7$ & 4,5 & $3-9$ & 3 & $1-5$ & 6 & $3-10$ & 4 & $2-5,5$ \\
\hline $\begin{array}{l}\text { вО, } \\
\text { балл }\end{array}$ & 30,5 & $22-38$ & $41^{*},++$ & $26,5-52$ & $44^{*},+$ & $34-49$ & $40^{*}$ & $33-46$ & $42 *,++$ & $34-55$ & 23 & $18-30$ \\
\hline
\end{tabular}

Примечание: * - п<0,05 по отношению к контролю; ++ - п<0,1 по отношению к группе БИ; ${ }^{\circ}$ - п<0,05 по отношению к группе ЛИ; \# - п<0,05 по отношению к группе ТИА; \#\# - п<0,1 по отношению к группе ТИА.

ЛТ не превышала контрольную в группах БИ (p>0,1), ЛИ (p>0,1) и ТИА (p>0,1). Обращал на себя внимание достаточно высокий уровень ЛТ у волонтеров, находящийся преимущественно в диапазоне умеренной тревожности (31-45 баллов) ? 58,8\%, при этом 41,2\% респондентов набрали более 45 баллов. Для всех остальных групп высокий уровень ЛТ, превышающий 45 баллов, был показан для БИ 59,1\% и ЦГК $58,3 \%$, что может свидетельствовать о существовании хронического фонового психоэмоционального напряжения. В группах ЛИ 46,3\% и ТИА 44,4\% доля высокой ЛТ не превышала таковую в контроле $(\mathrm{p}>0,1)$. Среди пациентов с ИБС у 20\% выявлен умеренный уровень ЛТ и в $80 \%$ - высокий.

В отношение PТ различий между группами в Мед выявлено не было. Обращало на себя внимание, что РТ у пациентов с ЛИ, ТИА, ЦГК и ИБС находилась в диапазоне умеренной тревожности, в группе БИ - преимущественно высокой (>45 баллов), обусловленной тяжестью неврологического дефицита. В процентном отношении у лиц с БИ преобладал высокий уровень РТ (72,7\%). Пациенты с ЛИ в 55,8\% случаев демонстрировали умеренный уровень и только в 44,2\% - высокий. Группы ТИА (51,9\% умеренный уровень и 48,\% высокий) и ЦГК (41,7\% умеренный и 41,7\% - высо- кий) имели равное соотношение между умеренным и высоким уровнем РТ. В отношение РТ при ИБС высокий уровень ее определялся в $57,1 \%$.

По результатам опросника Бека признаков клинической депрессии у опрошенных нами выявлено не было. У пациентов с различными формами ишемического повреждения головного мозга отличий балла от контроля не получено.

Иная картина имела место при субъективной оценке вегетативного статуса. У пациентов с БИ показатель ВО достоверно не отличался от контроля $(\mathrm{p}>0,1)$. Более высокий уровень дискомфорта был выявлен у лиц с ЛИ по сравнению с контролем $(\mathrm{p}<0,05)$ и пациентами с БИ $(\mathrm{p}=0,06)$. В группе ПНМК наибольшие значения отмечены нами при ТИА $(\mathrm{p}<0,01)$ и у лиц с ЦГК $(\mathrm{p}<0,01)$. В когорте ТИА балл ВО существенно превышал таковой для БИ $(\mathrm{p}<0,05)$. Учитывая высокий уровень ЛТ во всех сравниваемых группах и отсутствие отличий РТ, ситуацию можно объяснить соматизацией имеющегося хронического эмоционального напряжения [4].

Детализация параметров ВО указывала наибольшее субъективное вегетативное неблагополучие у пациентов с ИМ, как с БИ, так и с ЛИ (рисунок 1). По сравнению с контролем в этих группах преобладали жа- 
лобы на ощущение «перебоев в работе сердца» (72,7\% при БИ, 71,2\% при ЛИ и $11,8 \%$ в контроле; во всех случаях $p<0,05)$; чувство «нехватки воздуха» при волнении (72,1\% при БИ, 73,1\% при ЛИ и 23,5\% в контроле; $\mathrm{p}<0,05)$; учащенное дыхание (72,7\% при БИ, 73,1\% при ЛИ и 23,5\% в контроле; $\mathrm{p}<0,05)$. Постоянную потливость отмечали только пациенты с БИ $(68,2 \%$ при контроле $29,4 \% ; \mathrm{p}<0,05)$.

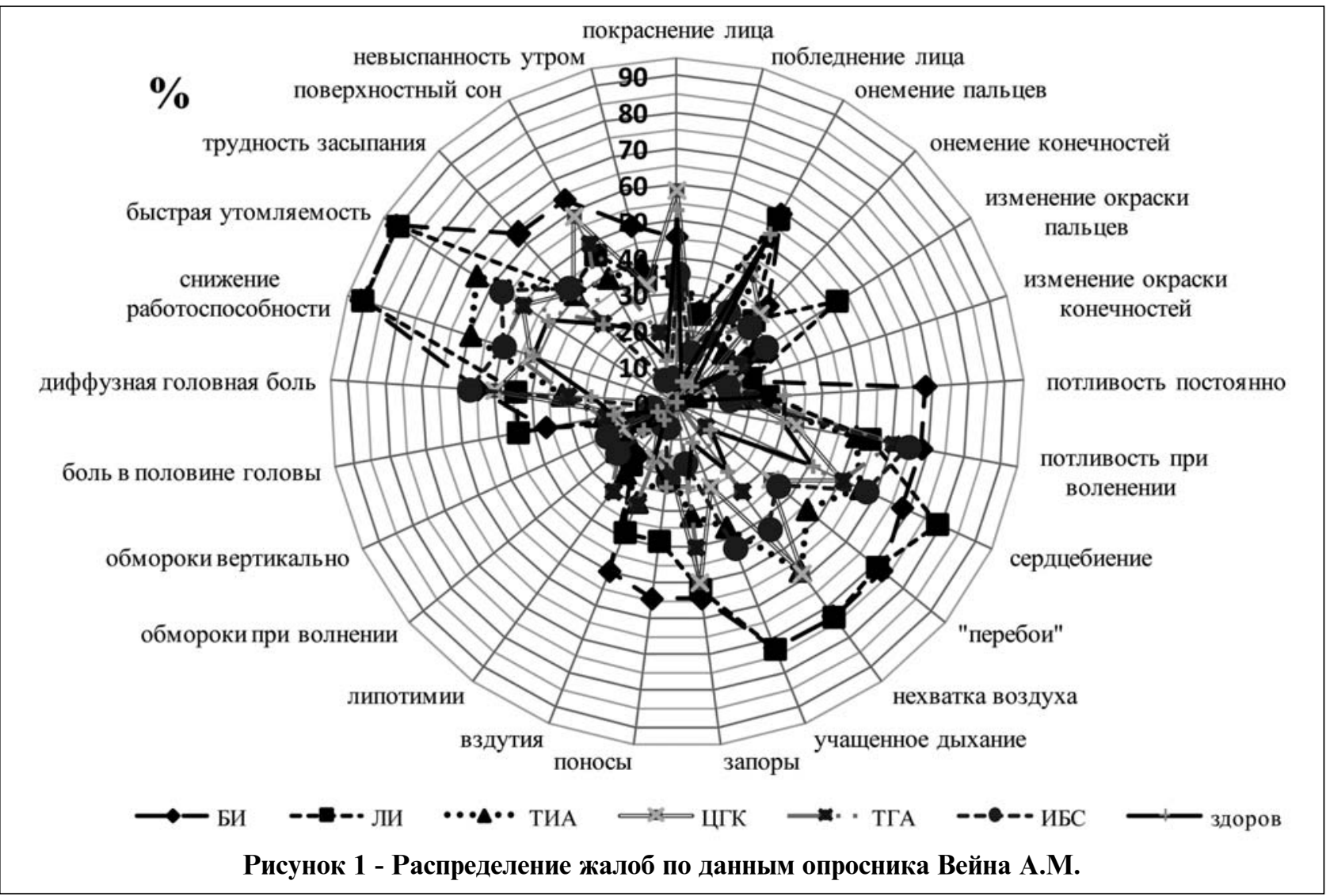

В несколько меньшем проценте случаев при БИ встречались жалобы на трудность засыпания $(63,6 \%$ и 29,4\% соответственно; $\mathrm{p}<0,05)$; поверхностный сон $(63,6 \%$ и $23,5 \%$; $\mathrm{p}<0,05)$; ощущение «невыспанности» утром $(50 \%$ и $34,6 \% ; p<0,05)$. При ЛИ спектр соответствующих симптомов несколько уменьшался: жалобы на нарушение ночного сна имели место только в 46,2\% (в контроле $23,5 \%$; $\mathrm{p}=0,06$ ); снижение утренней активации было отмечено у 34,6\% пациентов (при 11,7\% в контроле; $\mathrm{p}<0,05)$. При ТИА спектр жалоб напоминал таковой у лиц с ИМ с несколько меньшей выраженностью симптоматики (рисунок 1): потливость при волнении была отмечена в 50\% $(\mathrm{p}<0,05)$; «перебои в работе сердца» - в 46,3\% $(\mathrm{p}<0,05)$; чувство «нехватки воздуха» - в 57,4\% случаев $(\mathrm{p}<0,05)$; учащенное дыхание при вол- нении - у 37\% обследованных ( $<<0,05)$. У пациентов с ЦГК основными отличиями от контроля были жалобы на чувство «нехватки воздуха» при волнении (58,3\% и 23,5\% соответственно; $p<0,05)$; запоры $(50 \%$ и $23,5 \%$; $p=0,08)$ и поверхностный сон $(58,3 \%$ и $23,5 \% ; p<0,05)$. У лиц с ИБС также имели место жалобы симпатического характера: повышенная потливость при волнении $(64,3 \%$ и $29,4 \%$ соответственно, $\mathrm{p}<0,05)$; «перебои в работе сердца» $(35,7 \%$ и $11,8 \% ; \mathrm{p}=0,06)$; диффузная головная боль $(58,3 \%$ и $23,5 \%$; $<<0,05)$.

Полученные данные предполагали значительную активацию симпатического звена ВНС у пациентов с ИМ при любом объеме поражения мозгового вещества, а также при ПНМК и в группе сравнения [9].

При проведении корреляционного анали- 
за зависимости уровней ЛТ и РТ и вегетативных жалоб у лиц с БИ показано не было. У пациентов с ЛИ, однако, отмечена слабая положительная корреляционная связь между искомыми параметрами: ЛТ и ВО $(\kappa=0,34 ; \mathrm{p}<0,05) ;$ РТ и ВО $(\kappa=0,39 ; \mathrm{p}<0,05)$; балл по шкале Бека и ВО (к=0,32; $<<0,05)$. В группе ТИА также продемонстрирована положительная связь между психометрическими показателями и субъективным вегетативным статусом: ЛТ и ВО (к=0,3; $<<0,05)$; РТ и ВО (к=0,44; p<0,01); балл по шкале Бека и ВО (к=0,45; p<0,01). Пациенты с ЦГК имели высокую положительную корреляционную связь только между баллом по шкале Бека и BO (к=0,86; p<0,01). Для остальных групп связи между изучаемыми параметрами не определялось. Интересно, что при проведении корреляционного анализа между параметрами объективного вегетативного статуса и баллом ВО, положительная связь была выявлена только в группе БИ между условным показателем активности парасимпатического отдела ВНС и ВО (к=0,58; $p<0,05)$.

Таким образом, в результате проведен-

\section{СПИСОК ЛИТЕРАТУРЫ}

1. Karen, L. Furie Guidelines for the Prevention of Stroke in Patients With Stroke or Transient Ischemic Attack / Karen L. Furie, Scott E. Kasner, Robert J. Adams [at al.] // Stroke. -2011. - Vol. 42. - P. 227-276. 2. Аль-Хулайди Мохаммед, А.С. Нарушение когнитивных функций у больных с инфарктом мозга в раннем восстановительном периоде / А.С. Аль-Хулайди Мохамед // Пробл. здоровья и экологии. -2005. -- № 4. -- C. 82-86.

3. Боголепова, А.Н. Критерии диагностики и прогноза ишемического инсульта (клинико-нейропсихологическое исследование): Автореф. дис. ... д-ра мед. наук: 14.00.13 / А.Н. Боголепова; Моск. мед. академия. -- М., 2003.

4. Вейн, А.М. Вегето-сосудистая дистония / А.М. Вейн. - М., 2005. - 580 с.

5. Галиновская, Н.В. Значение оценки нейропсихологического статуса для определения реабилитационного прогноза у больных с последствиями мозгового инсульта и черепно-мозговой травмы / Н.В. Галиновская, Т.Д. Рябцева, И.Я. Чапко [и др.] // Мед. новости. -- 2005. -- № 2. -- С. 27-30.

6. Галиновская, Н.В. Сравнительный анализ психовегетативного статуса больных молодого возраста ного исследования было показано, что во всех группах с ишемическим повреждением головного мозга имел место высокий уровень ЛТ, при котором показатель РТ не превышал умеренный, независимо от тяжести заболевания. Наибольшее значение ЛТ при ИБС, вероятно, можно объяснить длительностью и хроническим течением патологического процесса. Выраженный субъективный вегетативный дискомфорт у пациентов с ЛИ и ТИА, положительно коррелировавший с ЛТ и РТ, выражался в активации симпатического звена ВНС по спектру субъективных жалоб, что подтверждало полученные нами ранее данные по объективному состоянию вегетативного статуca [15]. Что касается группы с ЦГК, в ней не было выявлено существенного повышения уровня ЛТ и РТ, где последняя имела тенденцию к более низкому значению по отношению к когорте лиц с ТИА $(\mathrm{p}=0,073)$. Однако в этой группе имела место тесная положительная связь между опросником депрессии Бека и субъективным дискомфортом, что требует дальнейших уточнений.

с ишемическим и аутоиммунным повреждением головного мозга / Н.В. Галиновская, Н.Н. Усова, В.Я. Латышева, Е.Ю. Чернявская // Мед. панорама. -2010. -- №. 11. -- С. 60-65.

7. Галиновская, Н.В. Сравнительный анализ вегетативного статуса у пациентов с преходящими и стойкими формами ишемического повреждения головного мозга / Н.В. Галиновская, Н.Н. Усова // Неврол. и нейрохирург. Восточная Европа. - 2012. - № 1 (13). - С. 43.

8. 1 Гусев, Е.И. Ишемия головного мозга / Е.И. Гусев, В.И. Скворцова. - М.: Медицина, 2001. - 328 с. 9. Лихачёв, С.А. Транзиторные ишемические атаки: этиология, патогенез, классификация, клиника, диагностика / С.А. Лихачев, А.В. Астапенко, Н.Н. Белявский // Мед. новости. -- 2003. --№ 10. -- С. 31-37. 10. Путилина, М.В. Особенности коррекции когнитивных нарушений у пациентов в остром периоде ишемического инсульта / М.В.Путилина, Н.В. Громадская, Н.Е. Лаздон [и др.] // Клиническая фармакология и терапия. -- 2005. --№ 3.Т. -- 14. -- С. 71-74. 11. Столяренко, Л. Д. Основы психологии: учеб. пособие для студ. вузов / Л. Д. Столяренко. - Ростовна-Дону: Феникс, 2005. - 672 с. 


\title{
XÜLASə
}

\section{BAŞ BEYNIN IŞEMIK ZəDӘLӘNMӘSİ OLAN XəSTӘLӘRDӘ PSIXOVEGETATIV STATUSUN ANALIZI}

\author{
${ }^{1}$ Smıçek V.B., ${ }^{2}$ Qalinovskaya N.V., ${ }^{2}$ Latışeva V.Ya., ${ }^{2}$ Usova N.N., \\ ${ }^{1}$ Vasilçenko N. V., ${ }^{2}$ Şaporova O.A., ${ }^{2}$ Marçuk V.N. \\ 1 "Respublika tibbi ekspertiza va reabilitasiya elmi-praktik mərkazi” dövlat müəssisasi, Minsk, Belarusiya; \\ 2"Qomel dövlat tibb universiteti” təhsil müassisasi, Gomel, Belarusiya
}

Tədqiqat beyin qan dövranının pozulmaları zamanı psixovegetativ statusun analizinə həsr edilib. Tədqiqat zamanı 48-74 yaş arasında 171 xəstə müayinə edilib. Nəticədə göstərilmişdir ki, baş beynin işemik zədələnməsi olan şəxslərdə simpatik şöbənin təsirinin üstünlüyü ilə qabarıq subyektiv vegetativ diskomfort, psixoloji narahatlıqla əlaqəli beyin toxumasının daha az zədələnməsi olan şəxslərdə daha əhəmiyyətlidir.

Açar sözlər: baş beyin infarktı, tranzitor işemik həmlə, serebral hipertenziv kriz, subyektiv vegetativ status, heyacanliliq, depressiya.

\section{SUMMARY}

\section{THE ANALYSIS OF THE PSYCHOVEGETATIVE STATUS IN PATIENTS WITH ISCHEMIC INJURY OF THE BRAIN}

\author{
${ }^{1}$ Smychek V.B., ${ }^{2}$ Halinouskaya N.V., ${ }^{2}$ Latisheva V.Y., ${ }^{2}$ Usava N.N., \\ ${ }^{1}$ Vasilcanka N.V., ${ }^{2}$ Shaparava O.A., ${ }^{2}$ Marchuk V.N. \\ ${ }^{1}$ Research Centre of the Medical Evaluation and Rehabilitation, Minsk, Belarus; \\ ${ }^{2}$ Gomel State Medical University, Gomel, Belarus
}

Research is devoted the analysis of the psychovegetative status at infringements of brain blood circulation for what 171 persons at the age from 48 till 74 years have been surveyed. It is as a result shown, those persons with ischemic damage of a brain the expressed subjective vegetative discomfort with prevalence of influence of sympathetic department, more significant for persons with smaller damage of the brain fabric, having communication with psychological trouble takes place.

Keywords: a brain heart attack, tranzitornaə ischemic attack, cerebral qipertenzivniy a crisis, the subjective vegetative status, uneasiness, depression.

Redaksiyaya daxil olub: 30.08 .2012

Çapa tövsiyə olunub: 18.09.2012

Rəyçi: Z.M.Sadıxova, t.ü.f.d. dosent 